\title{
ON THE EFFICIENCY OF BEHAVIOURAL PUBLIC ECONOMICS POLICIES: AN EXPERIMENTAL STUDY
}

\author{
Emre ÖZYERDEN ${ }^{1}$
}

\begin{abstract}
Behavioral economics develops as an area with inferences and conclusions to help policy makers in public economics policies. In this study, the effectiveness of public policies formed by using the default choice manipulation and loss aversion concepts are examined through laboratory experiments. In the experiments, participants play a public goods game in groups of 4 . In the first experiment, the effect of compulsory staying in a default option on participants' decisions has been evaluated by comparing the pre- and post-treatment decisions. In the second experiment, the result screens of the participants after each public goods game rounds were framed as loss and gain. Waiting time and loss framing found to have no effect on decisions.
\end{abstract}

Keywords: Behavioural Economics, Nudge, Behavioural Public Economics

JEL Code: D91, C91.

\section{Introduction}

The information obtained from behavioral economics studies is beneficial for governments in developing public policies as well as the private sector. Accordingly, instead of traditional prohibitory or rewarding applications, policies which do not limit individuals' freedom of choice but direct them with a soft nudge to make the right choice for themselves or the society are adopted. An example of this type of policies can be seen in preferences to participate in private pension systems. When the default choice is changed to opt-out from opt-in, an increase was observed in the number of people staying in the system (Choi, Laibson, Madrian, \& Metrick, 2004; Madrian \& Shea, 2001).

In this study, the effectiveness of two applications of behavioural public policy is tested experimentally. The first one tests whether waiting in the default option has an effect on choices. In this experiment, participants first play a classic public goods game, then they cannot make choices by staying in a default option for differing lengths of period and lastly they play the classic game again. The other experiment is related to the framing of the results screen and tests whether the presentation of the results as gain or loss has an effect on the continuing choices. These experimental studies will shed light on the effectiveness of the methods that can be applied when preparing behavioral public policy.

1 Res. Asst., Hitit University Department of Public Finance, emreozyerden@hitit.edu.tr 


\section{Behavioural Public Policies}

Since the beginning of 2017, Turkey implements default option policy for the private pension system. According to this system, all employees with certain conditions are automatically included in the individual pension system (automatic participation system) and those who wish to exit the system need to indicate this (opt-out). In the other private pension system which is operative since 2004, the default option is that individuals are out of the system and they need to formally apply to join (opt-in). As of February 15, 2019, there are 6.8 million participants in this system, while there are 5.2 million participants in the automatic participation system in the 26 months period. It can be said that changing the default preference is effective with the automatic participation system.

Nevertheless, opting out from the system takes time due to various reasons, and the participants who participate in the system automatically have to pay one or two premiums, that is they cannot leave the system for a certain period of time. Additionally, the government plans a 3 -year mandatory stay in the system ${ }^{2}$. This situation damages the symmetry between different default choice situations, in addition to violating the libertarian paternalism notion of Thaler and Sunstein (2018). The first experiment in this study will test whether compulsory staying in the default option has an effect on choices.

Another practice that can be applied in behavioural public policies is about those who do not keep their individual savings in financial institutions. Kahneman and Tversky's (1979) Loss Aversion may be useful in this case. According to this theory, losses loom larger than gains. In this respect, rather than specifying how much they will earn when they keep their savings in financial institutions (gain situation), declaring how much they have lost (loss status) as long as they do not keep their savings in these organizations would be more effective for individuals. The second experiment in this study tests whether the result screens framed as loss form and gain form affect decisions.

\section{Experiment}

The first experiment consists of four applications. Participants form groups of 4 and play a public goods game. In this game, each participant in a group is given 100 tokens which would be converted to the exam points at the end of the experiment. Each participant independently determines how much of their tokens are kept in his/her private account and how much to be sent to the group account. Tokens held in the private account return without a change to the participant at the end of the experiment, whereas contributions of 4 group members to the group account are summed, then multiplied by a certain coefficient (all coefficients in the experiment was 1.6), and then divided by 4 and equally transferred to the group members. In other words, tokens in the personal accounts do not affect the tokens of the other group members, while the tokens sent to the group account are multiplied by a certain coefficient and are given back equally to all group members regardless of the amount they sent. Final earnings $\left(\pi_{i}\right)$ of group members:

$$
\pi_{i}=\text { private }_{\text {account }}+(\text { group account } * 1.6) / 4
$$

\footnotetext{
2 http://www.hurriyetdailynews.com/private-pension-system-to-be-compulsory-in-turkey-137164 (access date: 24.05.2019)
} 
The above-described process constitutes one round of the experiment. In all treatments of the experiment, participants played 5 rounds of the base public goods game as described above. Then, participants could not make a decision on their tokens in cooperative_ 1 and cooperative_ 5 treatments, for 1 and 5 rounds respectively, all the tokens were transferred to the group account. Similarly, the participants were not be able to make a decision in freerider_ 1 and freerider_5 treatments, for 1 and 5 rounds respectively, but in these cases all tokens were transferred to their personal accounts. In each treatment, after the compulsory group or private account rounds, the participants played 5 rounds of base public goods game again. Each participant was only able to participate in one application. With these applications, the impact of compulsory stay in a default on the preferences of the participants can be evaluated by comparing the decisions in the first and last 5 rounds, that is before and after compulsory stay treatments. The hypotheses are:

Hypothesis 1a: In cooperative_1 and cooperative_5 treatments, contributions to the group account will be higher in the last 5 rounds compared to the first 5 rounds. Similarly, in freerider_ 1 and freerider_ 5 treatments, contributions to the group account will be lower in the last 5 rounds compared to the first 5 rounds.

Hypothehis $1 b$ : In the cooperative_ 5 treatment, contributions to the group account will be higher than in the cooperative_ 1 treatment. Similarly, contributions to the group account will be higher in the freerider_1 treatment than in the freerider_5 treatment.

Hypothesis 1a states that a compulsory stay in a default option have an impact on the choices of the participants. The hypothesis $1 \mathrm{~b}$ suggests that an increase in compulsory waiting time would also be effective on choices.

The second experiment also includes a base public goods game similar to the one above, but the treatments differ in the result screens. In gain treatment, at the end of each round participants face a result screen that indicates participant would earn "160 tokens" in that round if him/her and all other group members were to send all the tokens to the group account. In loss treatment, participants were shown they would have earned "160 - actual tokens more" if him/her and all other group members were to send all the tokens to the group account. The hypothesis for this experiment is as follows:

Hypothesis 2: Contributions to the group account will be higher in the loss treatment than in the gain treatment.

\section{Results}

The experiments were carried out with 116 students at Hitit University in December 2018 and April 2019. Exam points were used as the reward medium ${ }^{3}$. The experiment was run over computers interactively and programmed in ztree 4.1.6 (Fischbacher, 2007). Each participant took only one treatment and treatments lasted around 45 minutes.

\footnotetext{
32 points for participation, 12 points maximum, and $\sim 8$ points on average.
} 
Table 1. The Results of the First Experiment

(average contributions to the group account)

\begin{tabular}{|c|c|c|c|c|c|c|}
\hline \multirow{2}{*}{ Treatment } & \multirow{2}{*}{$\mathrm{n}$} & \multirow{2}{*}{ Average } & \multirow{2}{*}{ Before } & \multirow{2}{*}{ After } & \multicolumn{2}{|c|}{ \# Zero Contributors } \\
\hline & & & & & Before & After \\
\hline cooperative_1 & 20 & 49.59 & 50.82 & 48.36 & 9 & 13 \\
\hline cooperative_5 & 24 & 27.22 & 29.02 & 25.42 & 21 & 34 \\
\hline freerider_1 & 8 & 44.65 & 41.85 & 47.45 & 11 & 11 \\
\hline freerider_5 & 20 & 31.90 & 34.71 & 29.10 & 12 & 12 \\
\hline
\end{tabular}

Table-1 shows the results for the tokens transferred to the group account in the first experiment. In all the treatments except the freerider_1, average transfers to the group account are not in line with our hypotheses, however these differences are not statistically significant according to Wilcoxon rank sum tests. On the other hand, the number of singular observations of zerocontributions appear to have increased after the compulsory wait on the cooperative_1 and cooperative_5 treatments. Nevertheless, only the difference in number of zero-contributions in cooperative_ 5 treatment was found to be significant $\left(X^{2}=3.9862\right.$, Fisher's exact test $\left.p=0.032\right)$. According to the panel hurdle regression with cooperative_1 and cooperative_ 5 data, only the coefficient of periods was negative and significant. This is in line with the case of diminishing contributions to the group account observed in previous public goods experiments.

Table 2. The Results of the Second Experiment (average contributions to the group account)

\begin{tabular}{cccc}
\hline & NGL $(\mathbf{n}=\mathbf{2 2})$ & NLG $(\mathbf{n}=\mathbf{2 2})$ & Total \\
\hline neutral & 31.40 & 32.19 & 31.76 \\
gain & 35.74 & 24.75 & 31.34 \\
loss & 30.35 & 29.74 & 30.04 \\
\hline
\end{tabular}

Table-2 shows the results of the second experiment. In the NGL application, the participants played a base public goods game for the first 5 rounds (neutral), it is followed by 5 rounds of gain treatment and then 5 rounds of loss treatment. In NLG application, the order of the gain and loss treatments changes. The differences in the table were not significant according to Wilcoxon rank sum tests. In the panel tobit regression, the coefficient of periods variable was negative and significant as it is in the first experiment. The coefficients of the dummy variables for loss and gain treatments were also significant, but the difference between the values of these coefficients (8.408 and 8.526, respectively) was not statistically significant.

As a result, we couldn't find a significant difference between our treatments. The main reason for this is that the number of observations is insufficient and it is planned to increase the number of observations with new experiments. 


\section{References}

Choi, J., Laibson, D., Madrian, B., \& Metrick, A. (2004). "For better or for worse: default effects and 401(k) savings behavior", D. Wise içinde, Perspectives on the Economics of Aging, ss. 81-121.

Fischbacher, U. (2007). "z-Tree: Zurich toolbox for ready-made economic experiments". Experimental Economics, pp. 171-178.

Kahneman, D., \& Tversky, A. (1979). "Prospect Theory: An Analysis of Decision under Risk". Econometrica, 47(2), ss. 263-291.

Madrian., B., \& Shea, D. (2001). "The power of suggestion: inertia in 401(k) participation and savings behavior". Quarterly Journal of Economics 116 (4), ss. 1149-1187.

Thaler, R., \& Sunstein, C. (2018). Dürtme, İstanbul, Pegasus. 